\title{
Acoustic Rhinometry in Nasal Provocation Tests in Children and Adolescents
}

\author{
Wandalsen GF, Mendes AI, Matsumoto F, Solé D
}

\author{
Division of Allergy and Clinical Immunology, Department of Pediatrics, Federal University of São Paulo \\ (UNIFESP), São Paulo, Brazil
}

J Investig Allergol Clin Immunol 2016; Vol. 26(3): 156-160

doi: 10.18176/jiaci.0036

\begin{abstract}
Objectives: To standardize acoustic rhinometry (AR) in nasal provocation tests (NPTs) with histamine in children and adolescents Patients and Methods: We performed a cross-sectional validation to compare AR with anterior active rhinomanometry (AAR) during histamine NPT in 20 children and adolescents with persistent allergic rhinitis and 20 controls. Changes in total nasal resistance (AAR) were compared with changes in nasal volume in the first $5 \mathrm{~cm}$ (V5).

Results: Compared with controls, patients with rhinitis had significantly higher mean total nasal resistance $\left(0.34 \mathrm{~Pa} / \mathrm{cm}^{3} / \mathrm{s} \mathrm{vs} 0.21 \mathrm{~Pa} / \mathrm{cm}^{3} / \mathrm{s}\right.$; $P=.01)$ and lower mean V5 values $\left(8.20 \mathrm{~cm}^{3}\right.$ vs $\left.9.24 \mathrm{~cm}^{3} ; P=.04\right)$ at baseline. The mean histamine concentration necessary to increase total nasal resistance by at least $100 \%$ was significantly lower in the rhinitis group than in the control group $(0.72 \mathrm{mg} / \mathrm{mL} \mathrm{vs} 2.4 \mathrm{mg} / \mathrm{mL}$; $P<.001)$. At the end of the NPT a mean increase of $126 \%$ in total nasal resistance and a mean decrease of $24.3 \%$ in V5 were observed in the rhinitis group. When compared with the AAR criteria, the highest sensitivity and specificity values were observed for a cutoff represented by a 19\%-21\% drop in V5.

Conclusions: We found AR to be a feasible and sensitive tool for monitoring nasal response in children and adolescents undergoing histamine NPT. The best AR cutoff for ending the NPT was a 19\%-21\% drop in V5.
\end{abstract}

Key words: Rhinitis. Nasal provocation tests. Histamine. Acoustic rhinometry. Rhinomanometry. Nasal cavity. Airway resistance.

\section{Resumen}

Objetivos: Estandarizar la rinometría acústica (RA) como medida de la respuesta a la prueba de provocación nasal con histamina (PPN) en niños y adolescentes.

Pacientes y métodos: Se realizó un estudio de validación transversal comparando la RA frente a la rinomanometría anterior (RAA) activa en la evaluación de la respuesta frente a la PPN con histamina, realizado en 20 niños o adolescentes, diagnosticados de rinitis alérgica persistente y 20 controles sanos. Las variables estudiadas fueron los cambios en la resistencia nasal total, medida mediante RAA y los cambios en el volumen nasal de los primeros $5 \mathrm{~cm}$ (V5) evaluados mediante RA.

Resultados: En relación con los sujetos control, los pacientes con rinitis alérgica presentaban niveles basales de resistencia nasal total significativamente más elevados (medias respectivas $0,34 \mathrm{~Pa} / \mathrm{cm}^{3} / \mathrm{s}$ versus $0,21 \mathrm{~Pa} / \mathrm{cm}^{3} / \mathrm{s} ; \mathrm{p}=0,01$ ) y valores de V5 significativamente inferiores (medias respectivas $8,20 \mathrm{~cm}^{3}$ versus $9,24 \mathrm{~cm}^{3} ; p=0,04$ ). La concentración media de histamina necesaria para incrementar el $100 \%$ la resistencia total nasal fue significativamente más baja en los pacientes con rinitis que en los controles (medias respectivas $0,72 \mathrm{mg} / \mathrm{ml}$ versus $2,4 \mathrm{mg} / \mathrm{ml} ; \mathrm{p}<0,001$ ). Al final de la PPN el incremento medio de la resistencia nasal total fue del $126 \%$, en los sujetos con rinitis alérgica. En ese momento también se observó en este grupo un decremento medio del V5 del 24,3\%. Utilizando como patrón oro de respuesta positiva un incremento en la resistencia nasal total del 100\% mediante RAA, los puntos de corte con mayor sensibilidad y especificidad para el descenso de V5 se encontraban en un descenso de entre el 19 y $21 \%$.

Conclusiones: Nuestros resultados demuestran que la RA es una herramienta realizable y sensible para cuantificar la respuesta a la PPN en niños y adolescentes e identifican un punto de corte de descenso en el V5 de entre el 19 y el $21 \%$ como el de mayor sensibilidad y especificidad.

Palabras clave: Rinitis. Prueba de provocación nasal. Histamina. Rinometría acústica. Rinomanometría. Cavidad nasal. Resistencia de la vía respiratoria. 


\section{Introduction}

Nasal provocation tests (NPTs) have an important role in research on the symptoms, pathophysiology, and pharmacology of chronic rhinopathies such as allergic rhinitis [1]. NPTs make it possible to study the nasal mucosa in a safe and noninvasive manner by simulating allergic and irritative reactions [1].

NPTs are performed by the instillation of 1 or several concentrations of agents able to provoke a local response and induce symptoms and/or changes in nasal airflow. Histamine is one of most widely used pharmacological agents in nonspecific NPTs, and histamine NPTs have proven able to discriminate between patients with rhinitis and controls [2].

NPTs can be monitored in different ways, but objective measures are recommended to give the test better credibility and reproducibility $[1,3,4]$. Of the several parameters studied to monitor NPTs, nasal resistance remains the most widely standardized one $[1,3,5]$. Nasal resistance can be calculated using rhinomanometry, a technique that simultaneously measures pressure and airflow in the nasal cavity.

Acoustic rhinometry (AR) is a relatively new technique that was designed to evaluate nasal geometry based on the emission and reflection of acoustic waves in the nasal cavity and measurement of nasal volume and cross-sectional area [6]. Unlike other techniques, AR does not depend on patient cooperation and is considered suitable for the study of children $[7,8]$. Several studies have shown that evaluation of nasal volumes using AR is reliable and reproducible [9].

Until now, a limited number of studies have used AR to monitor NPTs, mainly in adults [10-13]. The use of AR in NPTs in children has not been standardized. Therefore, the objective of the present study was to standardize AR in NPTs with histamine in children and adolescents.

\section{Methods}

\section{Participants}

The study population comprised children and adolescents (aged 7 to 18 years) with and without allergic rhinitis. The rhinitis group was composed of patients who had had moderateto-severe allergic rhinitis for more than a year and were in regular follow-up at a specialized outpatient clinic. All of the patients had a positive skin prick test result (mean wheal diameter $\geq 3 \mathrm{~mm}$ ) to at least 1 inhaled allergen from the following group: Dermatophagoides pteronyssinus, Dermatophagoides farinae, Blomia tropicalis, dog and cat dander, Periplaneta americana, Blattella germanica, fungi, and pollen mixture (IPI-ASAC). Patients with anatomic abnormalities in the upper airway and patients who had received topical nasal corticosteroids or had a respiratory infection in the previous month were excluded. Oral antihistamines, when taken, were suspended at least 1 week before the NPT.

The control group was composed of children and adolescents in the same age range with no persistent or recurrent nasal symptoms and no clinical history of allergic rhinitis or other atopic diseases. Physical examination revealed that the controls had a healthy upper airway, and the skin prick test result was negative for all of the allergens used in the skin prick test. The members of the control group had no history of treatment with topical nasal corticosteroids or oral antihistamines.

\section{Nasal Provocation Tests}

NPTs were performed in a room with controlled temperature $\left(20^{\circ} \mathrm{C}-25^{\circ} \mathrm{C}\right)$ and humidity $(50 \%)$ after 20 minutes of acclimatization. Nasal responses were monitored using AR and active anterior rhinomanometry (AAR; SRE 2000, Rhinometrics). These techniques were performed by the same trained operator and according to international recommendations [14]. During the test, the child remained seated without extending the neck. Inspiratory nasal resistance at $75 \mathrm{~Pa}$ was measured 3 times, and the mean value recorded. To calculate total nasal resistance (TNR), resistance in the left nostril was multiplied by resistance in the right nostril and the product was divided by the sum of both resistance values [14]. Nasal volumes were also measured 3 times, and the mean value of each nostril was added to obtain total nasal cavity values [14]. According to previous recommendations, the volume of the first $5 \mathrm{~cm}$ (V5) was selected for analysis [15].

Baseline measurements of V5 and TNR were obtained after instillation of $0.15 \mathrm{~mL}$ of saline. After that, $0.15 \mathrm{~mL}$ of increasing concentrations of isotonic histamine dihydrochloride $(0.12,0.25,0.5,1.0,2.0,4.0$, and $8.0 \mathrm{mg} / \mathrm{mL}$ [IPI-ASAC] $)$ were sprayed into both nostrils at room temperature. V5 and TNR were measured 5 minutes after each instillation in a random order. Patients were instructed to take a deep breath and then hold their breath for a few seconds immediately before instillation of histamine [3]. NPT results were considered positive, and the test was stopped when TNR increased by at least $100 \%$ [16].

Three drops of topical nasal decongestant (oxymetazoline, $0.5 \mathrm{mg} / \mathrm{mL}$ ) were applied in each nostril after the end of the NPT, and a final measurement of V5 and TNR was taken after 10 minutes.

This study was submitted to and approved by the local ethics committee (protocol no. 0705/04). Written informed consent was obtained from all parents.

\section{Statistical Analysis}

Parametric and nonparametric tests were used in the statistical analysis. The sample size was estimated based on a mean decrease of $15 \%$ in V5 values after the NPT [13,17]. At least 16 individuals in each group were necessary to reach a statistical power of $80 \%$ and significance of $5 \%$.

In order to determine the optimal AR cutoff point for the end of the NPT, the sensitivity, specificity, and area under the receiver operating characteristic (ROC) curve of cutoff points in the range of a $14 \%-30 \%$ reduction in V5 were compared with a $100 \%$ increase in TNR.

\section{Results}

Twenty-five patients were included in the rhinitis group and 24 in the control group. Three patients were excluded from the rhinitis group owing to technical difficulties in rhinomanometry and 2 owing to lack of cooperation. In the 


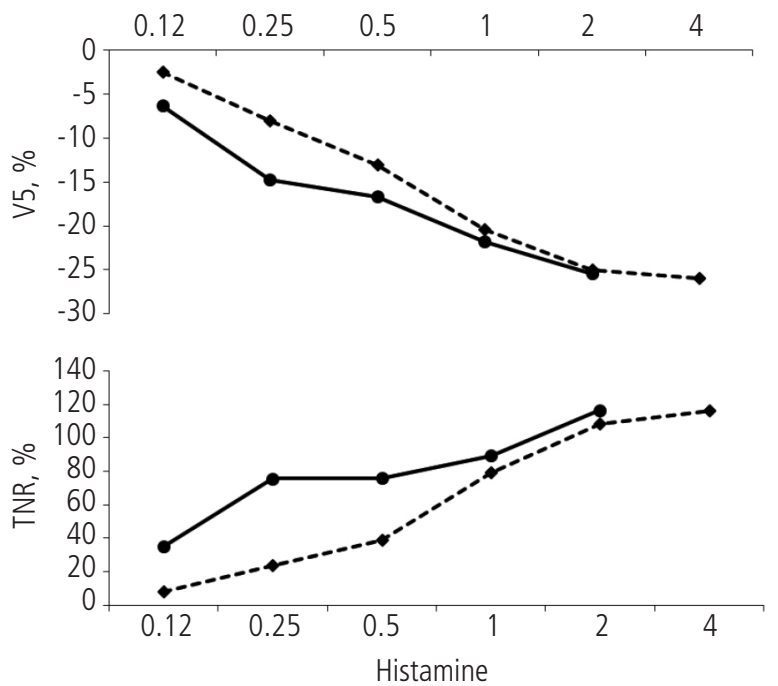

Rhinitis $\rightarrow-$ Controls

Figure 1. Mean percentage change from baseline in total nasal resistance (TNR) and the volume of the first $5 \mathrm{~cm}$ of the nasal cavity (V5) after instillation of each concentration of histamine $(\mathrm{mg} / \mathrm{mL})$ in the rhinitis group and the control group.

control group, 2 children were excluded owing to recent respiratory infections and 2 owing to technical reasons.

The mean age of the rhinitis patients and controls was 11.8 years and 13.4 years, respectively. Boys accounted for 9 patients and 8 controls. No severe adverse events were observed during the NPTs.

Compared with controls, patients with rhinitis had significantly higher mean TNR values $\left(0.34 \mathrm{~Pa} / \mathrm{cm}^{3} / \mathrm{s}[95 \% \mathrm{CI}\right.$, $0.26-0.42]$ vs $0.21 \mathrm{~Pa} / \mathrm{cm}^{3} / \mathrm{s}$ [95\%CI, 0.18-0.24]; $\left.P=.01\right)$ and lower mean V5 values $\left(8.20 \mathrm{~cm}^{3}\right.$ [95\%CI, 7.59-8.81] vs 9.60 $\mathrm{cm}^{3}$ [95\%CI, 8.81-10.38]; $\left.P=.04\right)$ at baseline.

The mean percentage change from baseline in TNR and V5 after instillation of each concentration of histamine in both groups is shown in Figure 1. The mean histamine concentration needed to obtain at least a $100 \%$ increase in TNR among patients with rhinitis was $0.72 \mathrm{mg} / \mathrm{mL}$ (95\%CI, 0.42-1.02), which was significantly lower than that of the controls (2.4 mg/mL [95\%CI, 1.9-2.9]; $P<.001)$.

Among patients with rhinitis, the instillation of the last concentration of histamine was followed by a mean increase in TNR of $126 \%(95 \% \mathrm{CI}, 113 \%-139 \%)$ and a mean decrease in $\mathrm{V} 5$ of $24.3 \%(95 \% \mathrm{CI}, 22.3 \%-26.3 \%)$. After administration of the decongestant, the mean TNR was $4 \%$ higher than baseline ( $95 \% \mathrm{CI},-9 \%$ to $17 \%)$, and V5 was, on average, $5 \%$ higher than baseline $(95 \% \mathrm{CI},-1 \%$ to $11 \%)$. The percentage of patients with allergic rhinitis and controls who remained in the NPT after the instillation of each histamine concentration is shown in Figure 2.

The sensitivity and specificity of the different AR cutoff points (\% reduction in V5) for the end of the histamine NPT compared with the AAR are shown in the Table. The highest areas under the ROC curve were observed for a reduction in V5 of between $19 \%$ and $21 \%$ (Figure 3 ).

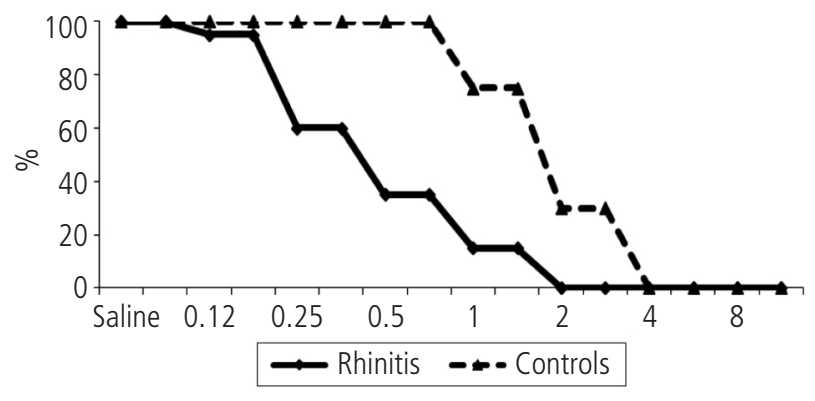

Figure 2. Percentage of patients with allergic rhinitis and controls who remained in the nasal provocation test after instillation of each histamine concentration $(\mathrm{mg} / \mathrm{mL})$.

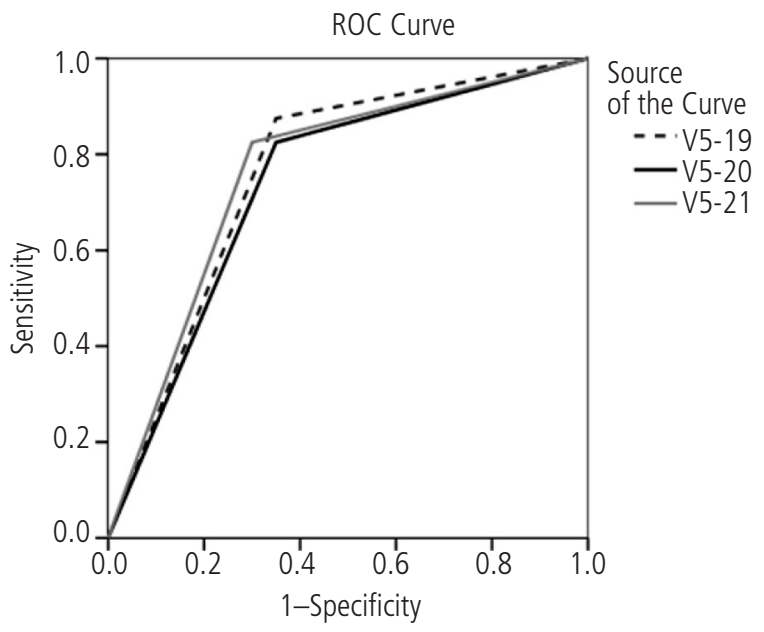

Figure 3. Area under the ROC curve for the acoustic rhinometry cutoff point $(19 \%-21 \%$ drop in the volume of the first $5 \mathrm{~cm}$ of nasal cavity [V5]) that indicated the end of the nasal provocation test. ROC indicates receiver operating characteristic.

\section{Discussion}

AR is a very promising technique that is associated with a growing number of favorable findings; however, no consensus has been reached on the use of AR for monitoring NPT. In fact, several authors have reported unsatisfactory results [10,18-20]. Phipatanakul et al [10] did not observe a good correlation between AR variables and nasal symptoms in patients undergoing specific NPT with cat antigens. In patients with occupational rhinitis undergoing specific NPT, Castano et al [18] found a significant correlation between AR and symptoms only when the analysis was restricted to cases showing a decrease in nasal volume greater than $40 \%$ from baseline values. Hellgren et al [19] reported that AR was not superior to other objective methods for monitoring of adults undergoing histamine NPT and was unable to discriminate patients from controls. Keck et al [20] reported that AR, unlike rhinomanometry, was not sensitive enough to detect changes after challenges with mite antigens in patients with perennial allergic rhinitis. The findings of these studies raise a series 
Table. Sensitivity and Specificity of Different Cutoff Points of Acoustic Rhinometry (\% Reduction in V5) for the End of the Histamine Nasal Provocation Test Compared With Active Anterior Rhinomanometry (100\% Increase in Total Nasal Resistance)

\begin{tabular}{llll}
\hline $\begin{array}{l}\text { Reduction in } \\
\text { V5, } \%\end{array}$ & Sensitivity, $\%$ & Specificity, $\%$ & AUC \\
\hline 14 & 95.0 & 40.0 & 0.675 \\
15 & 95.0 & 40.0 & 0.675 \\
16 & 90.0 & 47.5 & 0.688 \\
17 & 87.5 & 47.5 & 0.713 \\
18 & 87.5 & 55.0 & 0.700 \\
19 & 87.5 & 65.0 & 0.763 \\
20 & 82.5 & 65.0 & 0.738 \\
21 & 82.5 & 70.0 & 0.763 \\
22 & 72.5 & 72.5 & 0.725 \\
23 & 62.5 & 82.5 & 0.725 \\
24 & 50.0 & 87.5 & 0.688 \\
25 & 45.0 & 90.0 & 0.675 \\
26 & 40.0 & 90.0 & 0.650 \\
27 & 35.0 & 92.5 & 0.638 \\
28 & 32.5 & 95.0 & 0.638 \\
29 & 30.0 & 97.5 & 0.650 \\
30 & 20.0 & 97.5 & 0.588 \\
\hline & & &
\end{tabular}

Abbreviation: AUC, area under the receiver operating curve.

of questions. Initial studies with AR evaluated only minimal cross-sectional area [19], which is known to be less responsive to provocation than nasal volume $[14,21]$. Other authors evaluated changes in AR induced by NPT in large segments of the nasal cavity $(7.5-12.5 \mathrm{~cm})[10]$ and excluding the anterior portion of the nasal cavity, which is the most reactive area and where AR is more accurate [5,14]. Finally, the reactions observed in patients with seasonal allergic rhinitis outside the pollen season [19] or in patients with occupational rhinitis [18] cannot be extrapolated to those observed in patients with perennial or persistent rhinitis.

Our data corroborate the results of most adult studies $[11,13,21-24]$ and confirm that AR is a practical and sensitive technique for monitoring NPT in children. To our knowledge, ours is one of the first studies to describe AR during NPT in children. Despite the inclusion of adolescents in the study group, a large percentage of our sample $(40 \%)$ was composed of children under 12 years of age.

The high success rate in both AAR and AR showed that each is feasible for monitoring TPN. Slight differences, however, were observed in favor of AR. Technical difficulties with AAR were responsible for the exclusion of 5 patients. Three patients with allergic rhinitis experienced total obstruction of 1 nostril during NPT, thus precluding the measurement of nasal resistance and the continuation of NPT. Two schoolchildren from the control group were unable to adequately coordinate breathing to enable measurement of nasal resistance and had to withdraw from the study. This finding had been reported by others and pointed out as one of the main advantages of AR over AAR $[5,8]$.

In the present study, we chose to evaluate not only the nostrils, but also the total nasal cavity. Evaluation of the total nasal cavity is thought to be more accurate and aims to minimize the possible effects of the nasal cycle, which are particularly likely to occur in prolonged NPT [12].

Another important finding of our study was the sensitivity of AR for detecting the decrease in nasal patency in a dosedependent manner, similar to that observed in rhinomanometry (Figure 1). Mucosal edema has already been documented as the main pathophysiological event induced by NPT, and we showed that it could be adequately monitored using AR.

The definition of an ideal cutoff point for the reduction in V5 to indicate the end of the NPT makes it possible to perform the NPT using AR as the only objective parameter. The best cutoff point in our study was a decrease of $19 \%-21 \%$ in V5. Compared with the standard value of AAR $(100 \%$ increase in TNR), this cutoff showed good specificity and acceptable sensitivity for defining when to end the NPT. It is noteworthy that TNR and V5 are distinct parameters and that while V5 reflects the geometry of the nasal cavity, TNR is a physiological variable that is measured dynamically during tidal breathing. The differences between these 2 variables were seen clearly in our previous study, where we demonstrated that although significant, the correlation between them was only moderate, with correlation coefficients of around 0.5 [15]. In this preliminary analysis of our data, we compared TNR (obtained by AAR) with several AR parameters (V5, V4, V2-5, and minimal cross-sectional area) at 3 points: baseline, after induction of nasal obstruction, and after administration of a topical decongestant. Since we found that V5 was the parameter with the highest correlation with TNR, we decided to use it in the present study [15].

No unanimous AR cutoff point for NPT is reported in the literature. Differences in NPT protocols and in AR parameters make accurate comparisons between studies very difficult. Márquez et al [13] found that a 20\% drop in nasal volume in adults was the best point at which to separate patients with allergic rhinitis from controls undergoing NPT with methacholine [13]. Similarly, Hellgren et al [19] found that minimal cross-sectional area was reduced by between $22 \%$ and $27 \%$ after histamine NPT in adults with and without seasonal rhinitis. Parvez et al [17] found that the patent nasal cavity (segment between 1.0 and $6.4 \mathrm{~cm}$ ) was reduced, on average, by $32 \%$ after challenge with a single dose of histamine in adults without rhinitis.

In conclusion, we found that AR is a feasible and sensitive tool for monitoring the nasal response in children and adolescents undergoing histamine NPT. Comparison with standard rhinomanometry criteria ( $100 \%$ increase in TNR) revealed that the best AR cutoff point to indicate the end of the NPT was a decrease of $19 \%-21 \%$ in V5.

\section{Funding}

This study was funded FAPESP and CAPES.

\section{Conflicts of Interest}

The authors declare that they have no conflicts of interest. 


\section{References}

1. Litvyakova L, Baraniuk J. Nasal provocation testing: a review. Ann Allergy Asthma Immunol. 2001;86(4):355-64.

2. Giannico R, Oliveira C, Solé D, Naspitz C. Non-specific nasal provocation in children with chronic allergic rhinitis. J Investig Allergol Clin Immunol. 1996;6(2):110-6.

3. Malm L, Gerth van Wijk R, Bachert C. Guidelines for nasal provocations with aspects on nasal patency, airflow, and airflow resistance. International Committee on Objective Assessment of the Nasal Airways. Rhinology. 2000;38(1):1-6.

4. Hellings P, Scadding G, Alobid I, Bachert C, Fokkens W, Gerth van Wijk R, Gevaerts P, Guilemany J, Kalogjera L, Lund V, Mullol J, Passalacqua G, Toskala E, van Drunen C. Executive summary of European Task Force document on diagnostic tools in rhinology. Rhinology. 2012;50(4):339-52.

5. Roithmann R, Shpirer I, Cole P, Chapnik J, Szalai J, Zamel N. The role of acoustic rhinometry in nasal provocation testing. Ear Nose Throat J. 1997;76(10):747-50.

6. Hilberg 0 , Jackson A, Swift D, Pedersen O. Acoustic rhinometry: evaluation of nasal cavity geometry by acoustic reflection. J Appl Physiol. 1989;66(1):295-303.

7. Djupesland P, Pedersen 0 . Acoustic rhinometry in infants and children. Rhinol Suppl. 2000;16:52-8.

8. Scadding G, Hellings P, Alobid I, Bachert C, Fokkens W, Gerth van Wijk R, Gevaert P, Guilemany J, Kalogjera L, Lund V, Mullol J, Passalacqua G, Toskala E, van Drunen C. Diagnostic tools in Rhinology EAACl position paper. Clin Transl Allergy. 2011;1(1):2.

9. Uzzaman A, Metcalfe D, Komarow H. Acoustic rhinometry in the practice of allergy. Ann Allergy Asthma Immunol. 2006:97(6):745-51.

10. Phipatanakul W, Kesavanathan J, Eggleston P, Johnson E, Wood R. The value of acoustic rhinometry in assessing nasal responses to cat exposure. J Allergy Clin Immunol. 1998;102(6 Pt 1):896-901.

11. Ganslmayer M, Spertini $F$, Rahm F, Terrien M, Mosimann B, Leimgruber $A$. Evaluation of acoustic rhinometry in a nasal provocation test with allergen. Allergy. 1999;54(9):974-9.

12. Terrien M, Rahm F, Fellrath J, Spertini F. Comparison of the effects of terfenadine with fexofenadine on nasal provocation tests with allergen. J Allergy Clin Immunol. 1999;103(6):1025-30.

13. Marquez F, Sastre J, Hernandez G, Cenjor C, SanchezHernandez J, Sanchez J, Gutiérrez R, Sanabria J. Nasal hyperreactivity to methacholine measured by acoustic rhinometry in asymptomatic allergic and perennial nonallergic rhinitis. Am J Rhinol. 2000;14(4):251-6.

14. Clement $P$, Gordts F. Consensus report on acoustic rhinometry and rhinomanometry. Rhinology. 2005;43(3):169-79.

15. Wandalsen G, Mendes A, Solé D. Correlation between nasal resistance and different acoustic rhinometry parameters in children and adolescents with and without allergic rhinitis. Braz J Otorhinolaryngol. 2012;78(6):81-6.
16. Dordal $M$, Lluch-Bernal $M$, Sánchez $M$, Rondón $C$, Navarro A, Montoro J, Matheu V, Ibáñez M, Fernández-Parra B, Dávila I, Conde J, Antón E, Colás C, Valero A. Allergen-specific nasal provocation testing: review by the Rhinoconjunctivitis Committee of the Spanish Society of Allergy and Clinical Immunology. J Investig Allergol Clin Immunol. 2011;21(1):112.

17. Parvez L, Hilberg O, Vaidya M, Noronha A. Nasal histamine challenge: a reproducible model of induced congestion measured by acoustic rhinometry. Rhinol Suppl. 2000;16:4550.

18. Castano R, Trudeau C, Ghezzo H. Correlation between acoustic rhinometry and subjective nasal patency during nasal challenge test in subjects with suspected occupational rhinitis: a prospective controlled study. Clin Otolaryngol. 2010;35(6):462-7.

19. Hellgren J, Jarlstedt J, Dimberg L, Toren K, Karlsson G. A study of some current methods for assessment of nasal histamine reactivity. Clin Otolaryngol Allied Sci. 1997;22(6):536-41.

20. Keck T, Wiesmiller K, Lindemann J, Rozsasi A. Acoustic rhinometry in nasal provocation test in perennial allergic rhinitis. Eur Arch Otorhinolaryngol. 2006;263(10):910-6.

21. Nielsen L, Bjerke T, Christensen M, Pedersen B, Rasmussen $T$, Dahl R. Assessment of the allergic reaction in seasonal rhinitis: acoustic rhinometry is a sensitive and objective method. Clin Exp Allergy. 1996;26(11):1268-75.

22. Kim Y, Yang T, Lee D, Ko K, Shin S, Jang T. Evaluation of acoustic rhinometry in a nasal provocation test with allergic rhinitis. Otolaryngol Head Neck Surg. 2008;139(1):120-3.

23. Rondon C, Campo P, Herrera R, Blanca-Lopez N, Melendez L, Canto $G$, Torres M, Blanca M. Nasal allergen provocation test with multiple aeroallergens detects polysensitization in local allergic rhinitis. J Allergy Clin Immunol. 2011;128(6):1192-7.

24. Wang D, Raza M, Goh D, Lee B, Chan Y. Acoustic rhinometry in nasal allergen challenge study: which dimensional measures are meaningful? Clin Exp Allergy. 2004;34(7):1093-8.

- Manuscript received April 1, 2015; accepted for publication August 3, 2015.

\section{Gustavo F Wandalsen}

\author{
Rua dos Otonis 725 \\ São Paulo - SP 04025-002 \\ Brazil \\ E-mail: gfwandalsen@unifesp.br; \\ gfwandalsen@uol.com.br
}

